\title{
THE HISTORY OF ECONOMICS JOURNAL DATABASE COMPLEMENT 1969-2009 USER GUIDE
}

\author{
BY \\ JOSÉ EDWARDS AND FELIPE MARTIN
}

\section{INTRODUCTION}

Clarivate's Web of Science (WoS) Core Collection is today the most complete source of bibliometric information for history of economics journals: it includes the journals History of Political Economy (HOPE), the Journal of the History of Economic Thought (JHET), the European Journal of the History of Economic Thought (EJHET), and History of Economic Ideas (HEI). However, over the whole period of existence of these journals, WoS does not contain information for several documents. Therefore, the History of Economics Journal Database Complement 1969-2009 (JDC hereafter), completes the information missing in that collection. As of 2019, the JDC, together with the WoS Core Collection, include a total of 7,184 documents published in HOPE volumes 1-50 (1969-2018), JHET volumes 1-40 (1979-2018), EJHET volumes 1-25 (1993-2018), and HEI volumes 1-26 (1993-2018). These records include all cited references available in the different documents.

This User Guide describes the process of creating the JDC (section II), and explains the content (i.e., the variables) in that dataset (section III). In doing so, it suggests ways for using this new resource together with the WoS Core Collection.

\section{CREATING THE JOURNAL DATABASE COMPLEMENT 1969-2009}

Creating the JDC required, first of all, identifying all documents missing from the WoS Core Collection for HOPE, JHET, EJHET, and HEI. This process involved

José Edwards, Escuela de Gobierno, Universidad Adolfo Ibáñez (Chile), jose.edwards@uai.cl.; Felipe Martin, Universidad de Santiago (Chile), felipe.martinc@usach.cl. This User Guide is part of José Edwards's and Felipe Martin's project for the New Initiatives Fund of the History of Economics Society (HES): The Historiography of Economics Journal Database Complement 1969-2009 (2018). The dataset is available as an online appendix to this Letter (i.e., the whole 1969-2018 set), and also from the HES website (https://historyofeconomics.org/resources). 
comparing the information in the WoS Core Collection and the four journals for 1969 to 2009. Once identified, records for the missing documents were created by coding the respective information from the journals into the JDC using the WoS format. The objective was to create a dataset compatible with the WoS Core Collection. ${ }^{1}$

HOPE is accessible in the WoS Core Collection since its first volume (1969). However, not all documents are listed, with missing information for volumes 35, 36, 37 (i.e., 2003-2005), and also a few in several other years. Information for all missing documents was obtained from the HOPE website (https://read.dukeupress. edu/hope).

The JHET (or History of Economics Society Bulletin for 1979-1989) is available in the WoS Core Collection for volumes 31 (only partially) onwards (i.e., since 2009). The JDC thus comprises the entire volumes 1-30 and the missing items of volume 31 . The information for all missing documents was obtained from the JHET website (https://www.cambridge.org/core/journals/journal-of-the-historyof-economic-thought).

The EJHET is available in the WoS Core Collection for volumes 12 onwards (i.e., since 2005). It was, therefore, necessary to include volumes 1-11 in the JDC (also a few documents for 2007), and the information missing was obtained from the EJHET website (https://www.tandfonline.com/toc/rejh20/current).

$H E I$ is available in the WoS Core Collection from volume 17 onwards (i.e., since 2009). In this case, the information missing for volumes 1-16 was obtained not only from the journal's website (http://www.historyofeconomicideas.com) but also from JSTOR (https://www.jstor.org/journal/histeconidea) and from physical copies, because not all HEI issues are digitized. ${ }^{2}$

\section{USING THE JOURNAL DATABASE COMPLEMENT 1969-2009, TOGETHER WITH CLARIVATE'S WEB OF SCIENCE CORE COLLECTION}

Merging the JDC together with the WoS Core Collection (file available in the online appendix to this User Guide) allows for analyzing all documents published in $H O P E$, JHET, EJHET, and HEI for the last full fifty-year period (1969 to 2018).

\section{Documents}

Figure 1 represents the 7,184 documents in the whole dataset by year (dashed line), and also separately for the JDC (dark line; 2,514 documents) and the WoS Core Collection (gray line; 4,670 documents).

\footnotetext{
${ }^{1}$ Table 1, below, breaks down the content in both the JDC and the WoS Core Collection by document types, and also for HOPE, JHET, EJHET, and HEI (1969-2018).

${ }^{2}$ We are thankful to Nicola Giocoli, managing editor of $H E I$, for helping us access paper copies of the first volumes of this journal.
} 


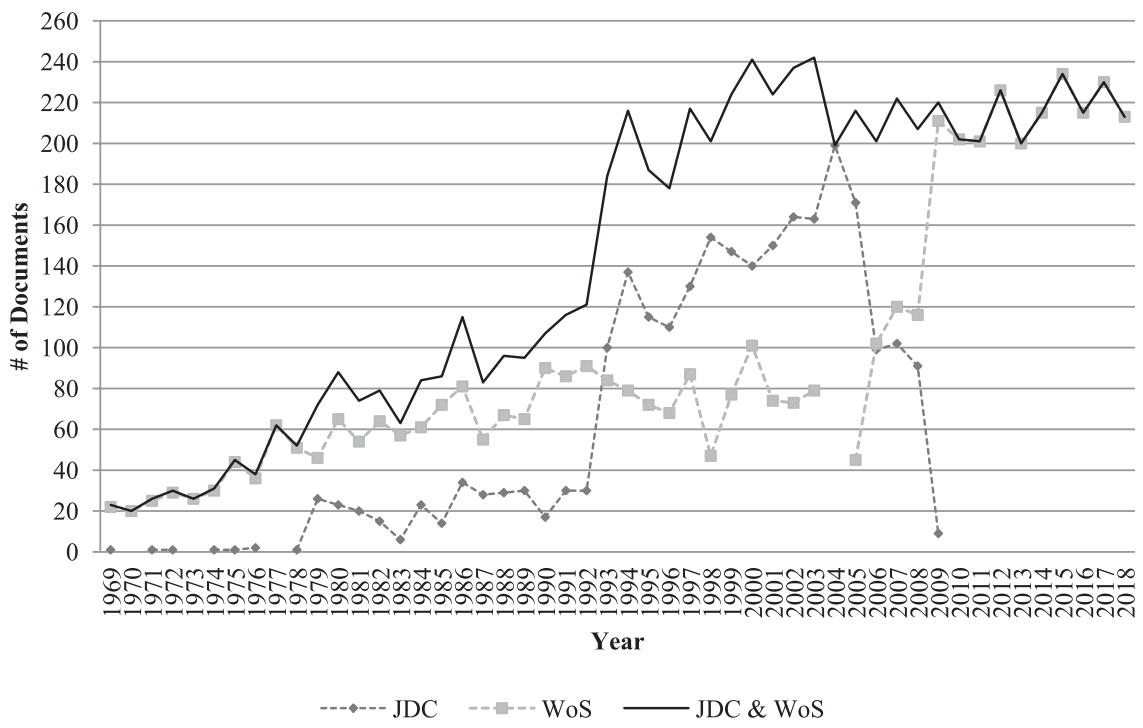

FIGURE 1. HOPE, JHET, EJHET, and HEI documents $(7,184)$ as in the JDC $(2,514)$ and WoS $(4,670)$.

\section{Variables}

Because the JDC was created to be compatible with the WoS Core Collection, it borrows the latter's variables list. Out of sixty-eight possible, the JDC contains information on the twenty-four following variables. ${ }^{3}$

\section{Publication Type (PT), Authors (AU, AF), Document Titles (TI), Publication Names (SO), and Languages (LA)}

The JDC is a journal database, and thus the Publication Type variable (PT) is always $\mathrm{J}=\mathrm{J}$ ournal. All authors (AU) and their full names (AF) are listed, and separated with semicolons (;) for coauthored documents. All Document Titles (TI) are listed as appearing in their respective journals (or Publication Names-SO; more below). The documents' Language (LA) is English, although there are a few titles (of Book Reviews) in mainly French, German, Italian, and Spanish.

Figure 2 reproduces the twenty most frequent names and concepts appearing in all document titles, by decades. They give an (admittedly rough) idea of the content in the dataset.

\section{Document Types (DT)}

Table 1 lists all documents in both the WoS Core Collection and JDC by Document Type (DT), and separated by Publication Names (SO). Of the 7,184 total, 3,721 are

\footnotetext{
${ }^{3}$ The forty-four other variables are either irrelevant (i.e., inapplicable to the JDC), created by Clarivate (i.e., specific to WoS and unavailable from the documents used for creating the JDC), or incomplete even in the WoS Core Collection. The full list of WoS field tags describing each variable is available at https://support. clarivate.com/ScientificandAcademicResearch/s/article/Web-of-Science-Core-Collection-List-of-fieldtags-in-output?language=en_US.
} 

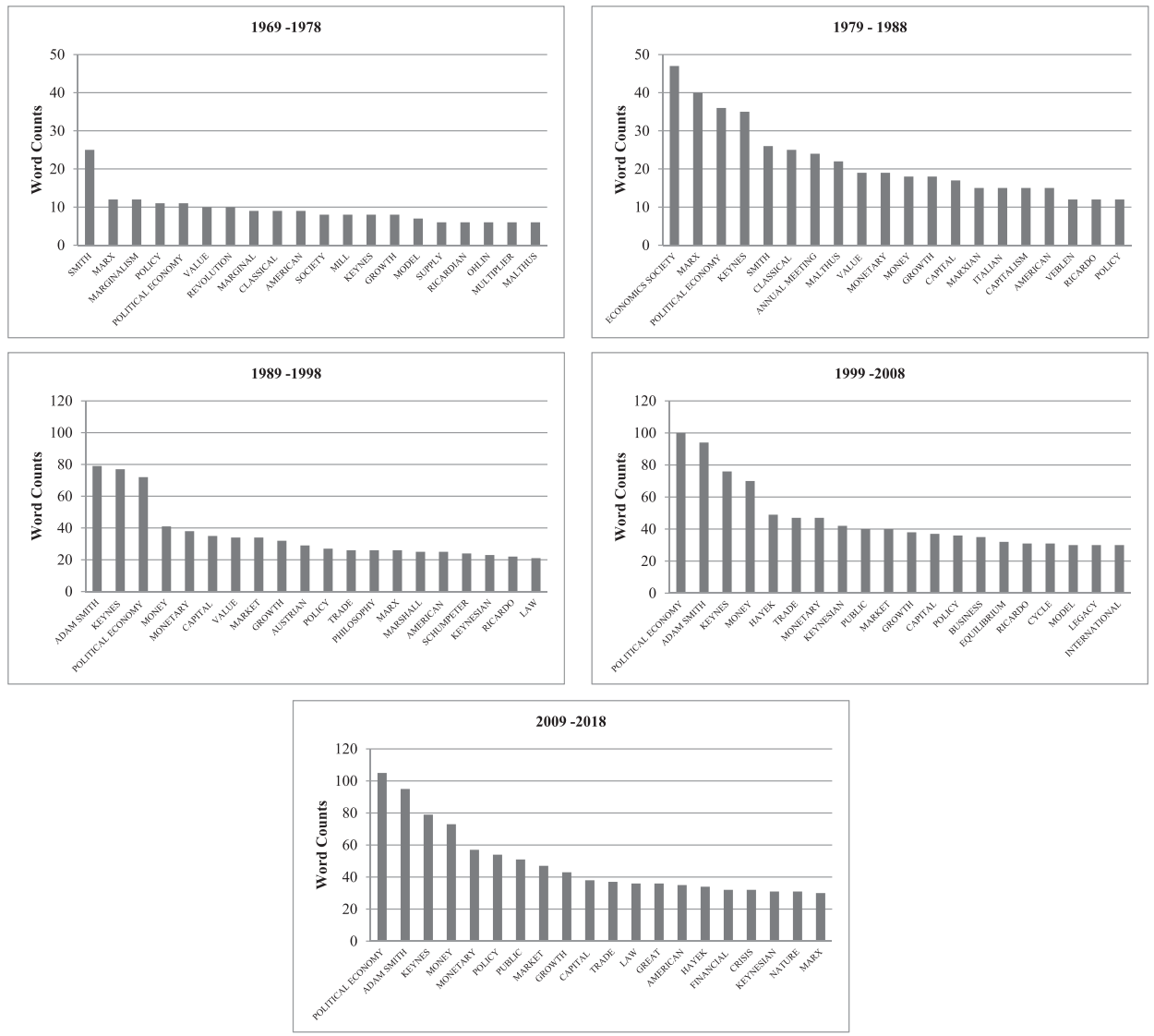

FigURE 2. 20 most frequent last-names and concepts, by decades (TI variable).

Articles or Proceedings Papers, 2,677 are Book Reviews, and 786 are other document types.

\section{Cited References (CR) and Cited Reference Counts (NR)}

Processing reference lists was (by far) the main task in creating the JDC, and most of the information in the dataset is listed under the Cited References (CR) variable. Cited Reference Counts (variable NR) contains the information of the number of cited references in the different documents. For a few early documents, which include their cited references in footnotes, NR counts the number of footnotes instead. Cited references are further discussed below.

Publishers (PU, PI, PA), International Standard Serial Numbers (SN), Source Abbreviations (J9, JI), Publication Years (PY), Volumes (VL), Issues (IS, SU, SI), and Pages (BP, EP, PG)

Information about the publishers of HOPE, JHET, EJHET, and HEI is included in variables PU, PI, and PA, as are the International Standard Serial Numbers (ISSNs) for 
Table 1. 3,084 HOPE, 1,530 JHET, 1,463 EJHET and 1,107 HEI Documents by Type (1969-2018)

\begin{tabular}{|c|c|c|c|c|c|c|c|c|}
\hline & \multicolumn{2}{|c|}{ HOPE } & \multicolumn{2}{|c|}{ JHET } & \multicolumn{2}{|c|}{ EJHET } & \multicolumn{2}{|c|}{ HEI } \\
\hline & JDC & WoS & JDC & WoS & JDC & WoS & JDC & WoS \\
\hline Article & 93 & 1621 & 471 & 235 & 234 & 379 & 285 & 202 \\
\hline Article; Proceedings Paper & 3 & 104 & - & - & - & 92 & - & 2 \\
\hline Bibliography & - & - & - & - & - & - & - & 1 \\
\hline Biographical-Item & 1 & 8 & 2 & 2 & - & 28 & 5 & 6 \\
\hline Book Review & 40 & 989 & 289 & 245 & 402 & 248 & 282 & 182 \\
\hline Correction & - & 1 & 3 & 1 & - & 8 & - & - \\
\hline Correction, Addition & - & 5 & - & - & - & - & - & - \\
\hline Editorial Material & 4 & 89 & 190 & 25 & 28 & 28 & 39 & 25 \\
\hline Item About An Individual & - & 13 & 3 & - & - & - & - & - \\
\hline Letter & - & 13 & 2 & 2 & - & - & 1 & - \\
\hline Note & 2 & 44 & 58 & - & 6 & - & 25 & - \\
\hline Reprint & - & 1 & - & - & - & - & - & - \\
\hline Review & 8 & 45 & - & 2 & - & 10 & 38 & 14 \\
\hline TOTAL & 151 & 2933 & 1018 & 512 & 670 & 793 & 675 & 432 \\
\hline
\end{tabular}

the four journals (SN), and abbreviations of their titles (J9, JI). Information about the publication Year, Volume, Issue, and Pages for each document is also available in the respective variables.

\section{Accession Numbers (UT)}

This variable serves as an identifier for each document in the WoS Core Collection. We created codes under this variable for all documents in the JDC using the form "JOURNAL/Volume/Issue/First-page." For example, EJHET01010047 identifies the document in EJHET Volume 1, Issue 1, and beginning on page 47.

\section{Reference Lists}

The variable Cited References (CR) contains the different cited references (either in a reference list or in footnotes), which are separated by semicolons. Cited Reference Counts (NR) correspond, indeed, to the number of semicolons within the CR variable for each document plus one. Figure 3 shows the total of 184,098 Cited Reference Counts (NR), by year, in both the JDC (47,899 cited references) and the WoS Core Collection $(136,199$ cited references). It reveals the growing number of cited references in these journals and the increase in the number of articles published as new journals were created and expanded, a trend that is also observable in academic literature more generally.

A simple processing of the Cited References (CR) variable allows for analyzing citations from all 7,184 documents published in HOPE, JHET, EJHET, and HEI (1969-2018). Some more processing — as the one described by François Claveau and Yves Gingras (2016) and José Edwards (Forthcoming)_allows for coupling the different documents by degrees of similarity of their cited references (i.e., making bibliographic couplings), and creating document networks. 


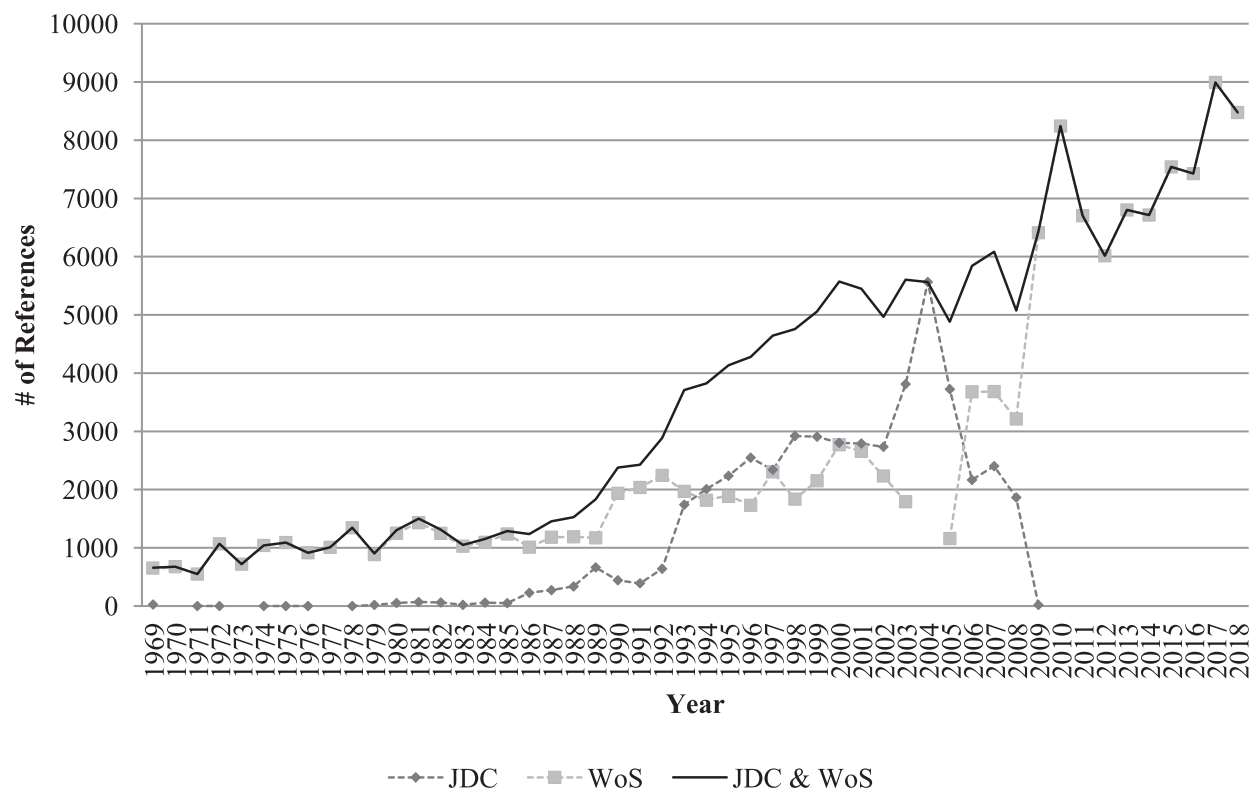

FigURE 3. Cited references in HOPE, JHET, EJHET, and HEI (184,098 references).

Figure 4 shows the result of a simple examination of the Cited References (CR) variable in both the JDC and the WoS Core Collection (1969-2018). It reveals the twenty most frequent economists' last names in all Cited References (CR), by decades. These occurrences represent $19.05 \%$ of the total cited references count, and suggest a few general trends for the citing practices of historians of economics during the last fifty-year period. ${ }^{4}$ Together with Figure 2, Figure 4 hints at a few dynamics over the last five decades, such as the prominence (still today!) of Joseph A. Schumpeter as a reference among historians of economics.

\section{CONCLUDING REMARKS}

This User Guide describes the process of creating the History of Economics Journal Database Complement (1969-2009) (JDC), together with a description of its content, which suggests (a few) ways for using this new resource.

As in the more general case of economic research, historians of economics are now also exploring new sources of information and methodologies (e.g., Edwards et al. 2018; Düppe and Weintraub 2019). The JDC will, we hope, help develop this new trend.

\footnotetext{
${ }^{4}$ The numbers in Figure 4 do not strictly represent cited references to authors with those last names, but instead word frequencies within the content of the CR variable. Unlike the JDC, the WoS Core Collection abbreviates the different items in CR, which makes the most frequent last names in Figure 4 decrease in the fifth decade (which is almost completely covered in WoS) as compared with the fourth. Relative shares remain similar, though—something one can check by processing the dataset.
} 

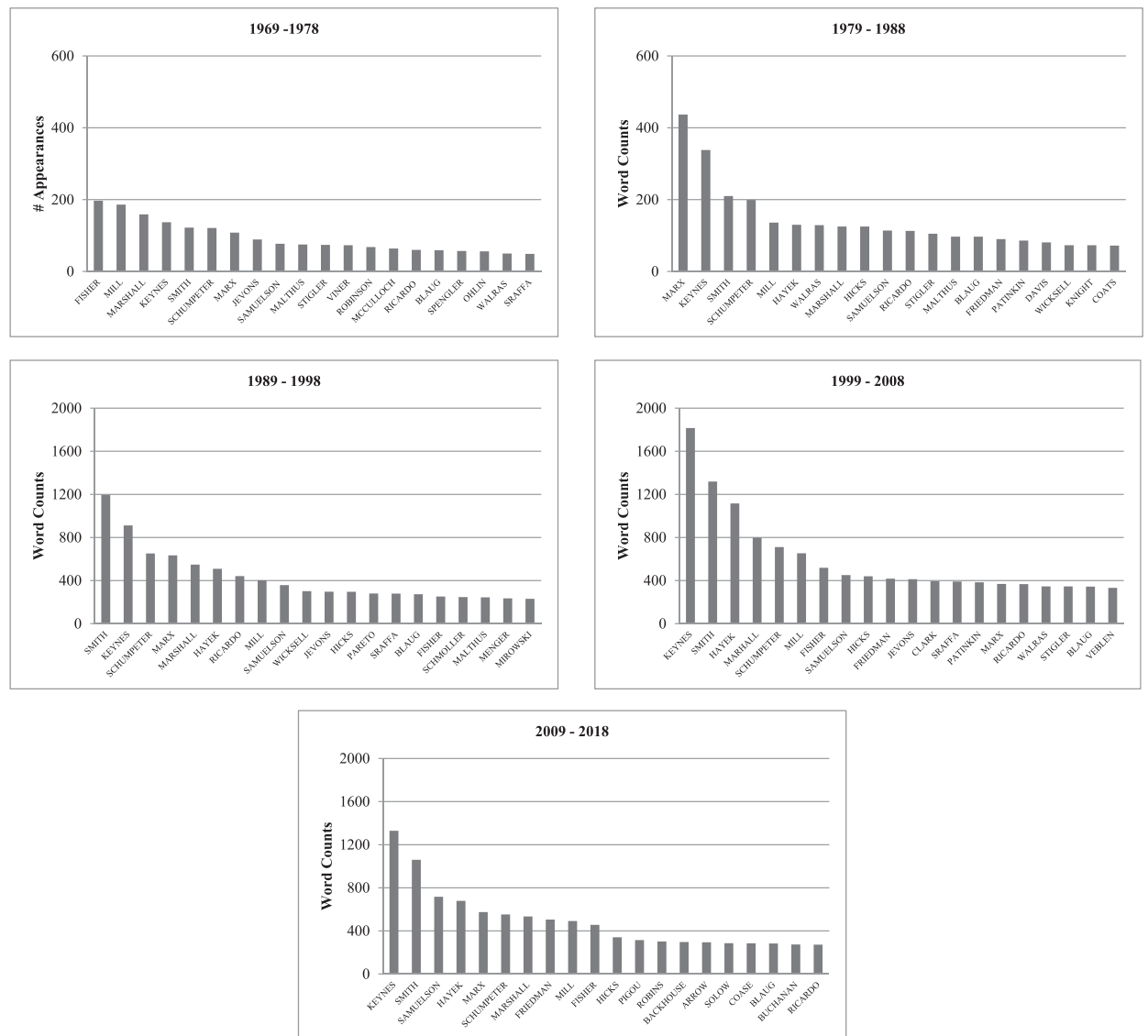

FiguRE 4. 20 most frequent economists' last-names, by decades (CR variable).

\section{SUPPLEMENTARY MATERIAL}

To view supplementary material for this article, please visit https://doi.org/10.1017/ S1053837219000440.

\section{REFERENCES}

Claveau, François, and Yves Gingras. 2016. "Macrodynamics of Economics: A Bibliometric History." History of Political Economy 48 (4): 551-592.

Düppe, Till, and Roy Weintraub, eds. 2019. A Contemporary Historiography of Economics. New York: Routledge.

Edwards, José. Forthcoming. "Fifty Years of HOPE: Changing Priorities in the Historiography of Economics." History of Political Economy 52 (1).

Edwards, José, Yann Giraud, and Christophe Schinckus. 2018. "A Quantitative Turn in the Historiography of Economics?" Journal of Economic Methodology 25 (4): 283-290. 